\title{
Implementation of Continuous Video-Electroencephalography at a Community Hospital Enhances Care and Reduces Costs
}

\author{
Brad J. Kolls ${ }^{1}$ Brian E. Mace ${ }^{1} \cdot$ Keith E. Dombrowski $^{1}$
}

Published online: 24 October 2017

(C) Springer Science+Business Media, LLC 2017

\begin{abstract}
Background Despite data indicating the importance of continuous video-electroencephalography (cvEEG) monitoring, adoption has been slow outside major academic centers. Barriers to adoption include the need for technologists, equipment, and cvEEG readers. Advancements in lower-cost lead placement templates and commercial systems with remote review may reduce barriers to allow community centers to implement cvEEG. Here, we report our experience, lessons learned, and financial impact of implementing a community hospital cvEEG-monitoring program.

Methods We implemented an adult cvEEG service at Duke Regional Hospital (DRH), a community hospital affiliate, in June of 2012. Lead placement templates were used in the implementation to reduce the impact on technologists by using other bedside providers for EEG initiation. Utilization of the service, study quality, and patient outcomes were tracked over a 3-year period following initiation of service.

Results Service was implemented at essentially no cost. Utilization varied from a number of factors: intensive care unit (ICU) attending awareness, limited willingness of bedside providers to perform lead placement, and variation in practice of the consulting neurologists. A total of 92 studies were performed on 88 patients in the first 3 years of the program, 24 in year one, 27 in year two, and 38 in year
\end{abstract}

Brad J. Kolls

kolls001@mc.duke.edu

1 Department of Neurology, Brain Injury Translational Research Laboratories, Duke University School of Medicine, 311 Research Drive, Bryan Research Building, DUMC 2900, Durham, NC 27710, USA three, showing progressive adoption. Seizures were seen in 25 patients (27\%), 19 were in status, of which 18 were successfully treated. Transfers to the main hospital, Duke University Medical Center, were prevented for 53 patients, producing an estimated cost savings of $\$ 145,750$. The retained patients produced a direct contribution margin of about $\$ 75,000$, and the margin was just over $\$ 100,000$ for the entire monitored cohort.

Conclusion ICU cvEEG service is feasible and practical to implement at the community hospital level. Service was initiated at little to no cost and clearly enhanced care, increased breadth of care, increased ICU census, and reduced transfers. The system allowed for successful management of ICU patients with underlying seizures and eliminated interfacility transfers, producing a savings of $\$ 145,750$. The savings combined with the retained patient revenue produced a total revenue of over $\$ 250,000$ with additional revenue in professional services as well. These results suggest expansion of cvEEG monitoring to community ICUs is practical, financially sustainable, improves the level and quality of care, and reduces costs.

\section{Keywords ICU EEG ·}

Continuous video-EEG monitoring - Community hospital . Cost $\cdot$ Business development $\cdot$ Implementation

\section{Introduction}

Despite a wealth of data to suggest that a significant proportion of hospitalized patients with altered mental status are having non-convulsive seizures, as well as an expert consensus statement indicating the importance of continuous video-electroencephalogram (cvEEG) monitoring, adoption of this form of monitoring has been slow outside 
of major academic centers [1-4]. Significant barriers to implementation exist outside large tertiary care centers, including expensive video-EEG acquisition equipment, data storage and handing resources, trained and certified EEG technologists, having an expert reader readily available to review and monitor the EEG study, and finally, limited experience in managing patients with recurrent non-convulsive seizures or non-convulsive status epilepticus. These barriers continue to be present in community hospital and even some academic centers.

Recent advances in technology may allow for more centers to conduct cvEEG monitoring of their patients. For example, EEG lead design and placement are easy enough to allow non-technologists to place them in some circumstances [5]. Latest versions of video-EEG acquisition hardware are easily networked to allow remote access and review of the study. Reliable internet connections to acquisition machines can allow the technologists and neurophysiologists easy access anywhere in the world (for example: www.nihonkohden.com, www.natus.com, www. cadwell.com). Finally, experts in neurocritical care and management of status can be instantly available in any hospital through telemedicine solutions. The hardware and network costs vary widely, but overall are significantly less than the cost of transferring patients for cvEEG monitoring and seizure management.

To gain insight into feasibility and best practices for how to implement a cvEEG-monitoring service in a community hospital, as well as begin to measure the financial impact and potential return on investment, we started an intensive care unit (ICU) cvEEG-monitoring program at a local community affiliate hospital, Duke Regional Hospital (DRH) in Durham, North Carolina. Here, we report methods of implementation, adoption, and utilization, and financial impacts of the service line in the first 3 years the service was created. A portion of this work has appeared in abstract form previously (Neurocritical Care Society meeting abstract 2015).

\section{Methods}

\section{Duke Regional Hospital}

DRH is a JCAHO-certified 369 bed community hospital that serves Durham, Orange, Person, Granville, and Alamance counties in North Carolina. Specializing in bariatric surgery and orthopedics, it has a variety of units dedicated to cardiac telemetry, general medicine, a chest pain unit, inpatient psychiatry, and an inpatient rehabilitation floor. The medical floors are staffed primarily by hospitalists with rotating academic general medical teams staffed by residents and hospitalists. The Emergency Department is fully staffed by emergency medicine-trained physicians. DRH is a primary stroke center.

At the time of service line initiation, there were 16 medical surgical intensive care beds with 6 stepdown beds contained within the ICU. The ICU was staffed by a private group of general intensivists and private practice pulmonologists and a small group of rotating academic pulmonology attendings. The unit is now staffed by the intensivists, a small group of advanced practice providers, and rotating fellows during the day. More recently, the unit has been expanded to 24 beds, but is still staffed by the same private and academic pulmonary intensivists, as well as two additional anesthesia trained intensivists.

At the time of service initiation, neurodiagnostic services were incorporated into the DRH special services along with cardiology diagnostics (electrocardiogram) and pulmonary functional testing. There were two neurodiagnostic technologists who were on a Monday through Friday schedule and were responsible primarily for intraoperative monitoring during the day along with ambulatory routine EEGs conducted in the afternoon. Neurology consult support consisted of private practice consultants for 34 weeks a year with on-site neurology fellows for the remaining 18 weeks.

\section{Service Line Design}

Several factors were considered when initially designing the service, particularly the limited technologist resources. Adding any additional case load could rapidly become overwhelming for the limited staff. Technologically, this system needed to automatically transfer data to our central cvEEG storage server for easy access and review using the same web-based tools setup for the main hospital cvEEG service. Additionally, there were no funds to support the implementation of the service so the cost needed to be as low as possible. Finally, evidence of benefit to the facility, patients, and providers needed to be demonstrated quickly or the service line would not be sustainable.

As such, the following model was developed and implemented:

1. To reduce the burden of the new service on the existing technologists, we chose to use electrode templates that would allow non-technologist providers already at the bedside to apply the leads when desired (Rhythmlink ${ }^{\circledR}$ product numbers BNT110-1020-4554, 5457, and 5762). Templates consist of non-latex, elastic straps, sewn together to allow proper position of electrodes in over the scalp; matching the 10/20 placement system. Holes were present at each electrode position to allow lead placement on the scalp and attachment to the template. Disposable, color-coded, subdermal needle or cup electrodes were used, connected to a headbox with corresponding color- 
coded connections for each electrode. The template cost varies with volume purchased. The starting price is \$35 US for the individual template and $\$ 100$ US if packaged with a full lead set of subdermal needles or cup electrodes. There are templates that allow different electrode numbers; however, templates with a full 10/20 electrode configuration were used as we have previously shown that reduced lead numbers results in reduced sensitivity for seizure detection [6]. Magnetic resonance imaging (MRI) compatibility is determined on the lead chosen; the templates themselves are MRI compatible.

2. To facilitate remote connectivity and shared storage resources, a collaboration between the Duke and DRH information technology (IT) staff was necessary. We leveraged the existing cvEEG infrastructure for the main hospital to remotely record to and store acquired data to the main hospital's neurodiagnostics server across a shared network. Monitoring of cvEEG was limited to the recently renovated ICU due to it now having available, unused data ports and the general principal that patients requiring monitoring should need a relatively high level of care (i.e., stepdown or ICU).

3. Given the limited budget available for this service line, a cvEEG-monitoring machine (Nihon Kohden Neurofax EEG-9100/9200 EEG software, Nihon Kohden, Tokyo, Japan) was moved from main Duke Hospital to the ICU of $\mathrm{DRH}$, as this equipment was being replaced by newer equipment from another vendor. This also facilitated the connectivity plan above as this device was already setup to send data directly to the primary storage and review server. A second element was petitioning the template manufacturer to provide a free sample of templates to initiate the program. This made initiation of the service essentially no cost, with a subsequent marginal cost of template purchase after a few months.

4. Core metrics of each case were abstracted and tracked in a quality assurance database of service utilization which was established prior to starting the service and was populated and maintained prospectively. The intent of the database was to be able to quantify use, determine impact, and to facilitate review of how the service evolved over time, as well as providing the basis for the assessment of outcomes and benefits created by the service to report to DRH leadership. Prior to preparing this manuscript, permission to publish from this quality assurance database was obtained from the Duke Institutional Review Board for Clinical investigations (Pro00068228).

\section{Education of Local Staff on Service Line}

As part of the implementation strategy, education around the availability, indications, and workflows associated with the cvEEG service was provided. The educational program consisted of a review of the indications for cvEEG monitoring, hands-on training in template application, and initiation of an EEG recording. An overview of how patients would be monitored, the communication pathway for reporting results, and the process for ordering a study were also reviewed. The entire training took 30-60 min. The education was offered daily for 14 days in a row, and for several evenings up to 10 p.m. to provide ample opportunity for all providers (nursing, respiratory therapy, clinical neurophysiology technologists, and ICU physicians) to participate and gain exposure and experience with the planned services and technologies.

\section{Results}

\section{Utilization and Service Adoption}

The service was launched on June 1 of 2012, and the first study was performed on June 27, 2012. Hookup was during the day, and the request was driven by the consulting neurologist. Over time, some requests came from the primary ICU team, others from the neurosurgery service, though the vast majority of requests were from the neurology consultants. Figure 1 summarizes the annual utilization and shows the monthly use per year. There was significant variability in use of the service within the first year with weeks to months between studies initially. This has slowly increased to an average of about 1 study every 2 weeks. Adoption and utilization has been somewhat slower than expected, in comparison with the medical ICU adoption in the first 3 years at the main Duke Hospital (Fig. 1). Despite the slow uptake, use of the service has been consistently growing annually. The medical ICU was chosen as a comparator since some of the same providers had worked in both units and the patient populations are similar. However, the DRH ICU has a much higher proportion of elective general and cardiothoracic surgical cases.

The primary indication for the cvEEG study was tracked and a summary of the indications is provided in Table 1. As shown, altered mental status, witnessed seizures, and cardiac arrest were the most common indications. Witnessed seizure activity was noted in 19/45 (42\%) of the altered mental status cases.

It was difficult to ascertain the duration from order or desired start time until actual EEG hookup, but it was relayed that it often took multiple hours until a study was initiated, particularly at night. In cases in which clinical seizure activity was reported, it was often necessary for one of the authors to hook up the study, especially in the first 18 months of the service. In all, 203 days of monitoring 

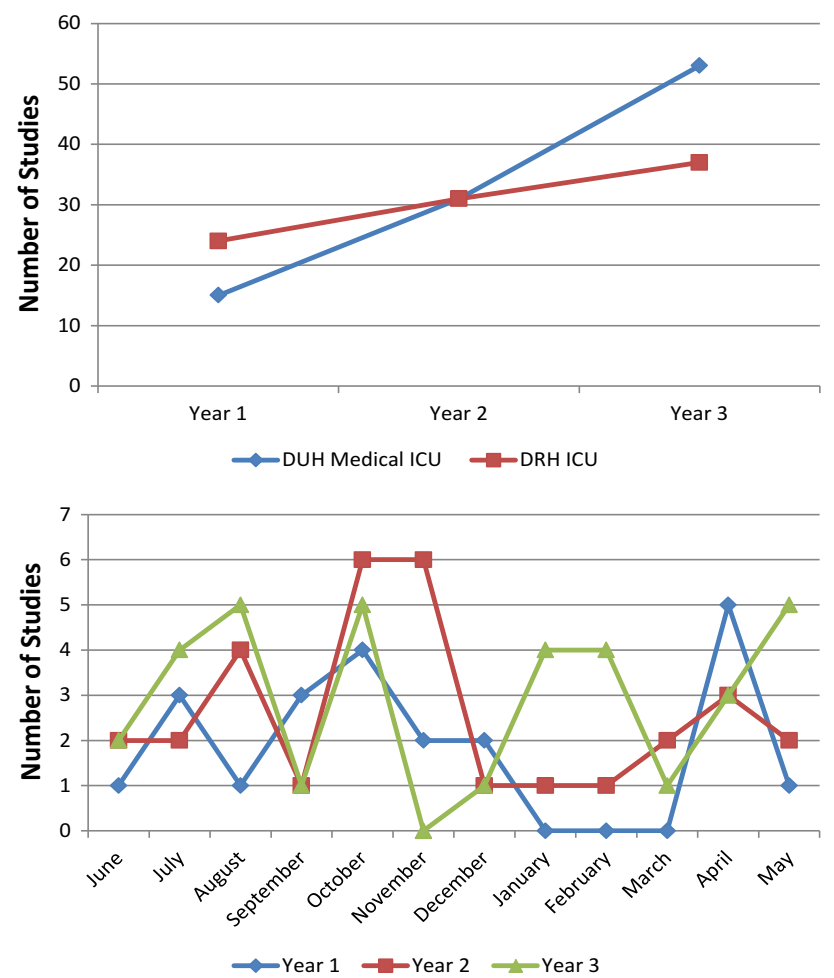

Fig. 1 Service utilization over the first 3 years of operation. The top panel shows a comparison of utilization between the medical intensive care unit (ICU) at the main hospital from 2008 to 2010, and the Duke Regional ICU (DRH) utilization from 2012 to 2015. Both periods represent the first 3 years of formal continuous videoEEG monitoring service at each facility. The bottom panel shows DRH monthly utilization of cvEEG by year

were performed as part of 92 study requests on 88 patients for an average monitoring period of 2.2 days per study.

\section{Study Interpretation and Communication of Results}

Two neurocritical care and clinical neurophysiology trained physicians provided the study interpretations following the American Clinical Neurophysiology Society recommended guidelines for interpretation and reporting [7]. Studies were generally reviewed within an hour of initiation and then again a few hours later to ensure seizures were not ongoing and missed. Most studies were read every 4-6 h during the day up until 22:00-00:00. Then, studies were reviewed again the following morning. A report was generally called once after study initiation to inform on the presence or absence of seizures. Additional calls were made for cases in which seizures were noted and being actively managed. For studies that did not require intervention, one call per day is made in the morning to the rounding team to provide a verbal read. Then, a report is filed to the chart. Guidance on therapy was typically provided by the dedicated neurologist who was on call for consults that week. It was preferred to have that provider
Table 1 Summary of the cvEEG utilization over first 3 years of service

\begin{tabular}{ll}
\hline General observations & Number of patients $(\%)$ \\
\hline Total study requests & 92 \\
Total patients studied & 88 \\
Total number of study days & 184 \\
Average duration of study (days) & 2.2 \\
Longest study duration (days) & 8 \\
Overall mortality & $24(26)$ \\
Death due to withdrawal/hospice & $23(96)$ \\
Transfer prevented & $53(58)$ \\
Transferred in for monitoring & $2(2)$ \\
Recorded with subdermal needles & $77(84)$ \\
\hline Indication for study & Number of patients $(\%)$ \\
\hline Altered mental status & $45(49)$ \\
Seizures & $22(24)$ \\
Cardiac arrest & $19(21)$ \\
Spells & $6(6)$ \\
\hline Cardiac arrest & Number of patients $(\%)$ \\
\hline Cardiac arrest & $19(21)$ \\
Death in arrest patients & $14(74)$ \\
Death due to withdrawal/hospice & $13(93)$ \\
\hline Seizures & Number of patients $(\%)$ \\
\hline Seizures present in study & $25(27)$ \\
Death in patients with seizures & $9(36)$ \\
Death due to withdrawal/hospice & $5(20)$ \\
Treatment success in seizures & $20(80)$ \\
Number in status epilepticus* & $19(76)$ \\
Treatment success in status & $18(95)$ \\
\hline St & \\
\hline
\end{tabular}

*Status was defined as multiple, frequent seizures every hour or continuous ictal activity on continuous video-EEG monitoring

drive clinical care and feedback to the ICU team regarding therapy decisions as they were directly evaluating the patients, interacting with families and following the clinical course. In some cases in which the on-site provider felt uncomfortable, or in afterhours periods requiring acute intervention decisions, the neurocritical care trained readers provided input on interventions and care. This is still the ongoing practice today.

\section{Template and Lead Safety and Performance}

As in our previous work with the templates, we found the EEG data obtained in these studies to be of high quality and good diagnostic accuracy [5]. The vast majority of studies were performed using subdermal needle electrodes secured to the template by EC2 cream (Grass Technologies) and 
paper tape. No needle stick injuries were reported during the 3 years of use, no infections of the scalp or adverse bleeding events were seen, even though a few patients were on aspirin, heparin, or had coagulopathies. The longest recording performed was for 8 days, and this only required touch-up of the leads once during that time. Recording quality was impressive given bed percussion, frequent suctioning, bathing, and other ICU 'noise.' Such activities are known to dislodge collodion leads over time (personal observations).

Skin breakdown or pressure ulcers were seen as a result of the template chinstrap in 4 cases. In one case, a surgical consult was required for concern of skin healing and scarring on the patient's chin. This led to the routine practice of using Mepilex dressings (Mölnlycke Health Care) over the chin and intermittent removal of the chin strap for an hour or so several times a day for patients undergoing more than $48 \mathrm{~h}$ of monitoring.

\section{Clinical Impact}

We considered a demonstration of a prognostic pattern in cardiac arrest (i.e., seizures or status epilepticus, discontinuous background, no changes in background with stimulation) [8-11], identification of seizures and status epilepticus, and prevention of interfacility transfer for EEG monitoring to be a measure of clinical impact.

There were a total of 19 cardiac arrest cvEEGs performed over the 3-year period. Mortality was high, $14 / 19$ (74\%) for this cohort of patients. Of the 14 deaths, 13 were withdrawal of care or transfers to hospice (Table 1). Unfortunately, our database does not contain all cardiac arrest patients, just those that underwent cvEEG monitoring, so it is not clear what the overall mortality and cvEEG utilization for this group was over time. However, we did see increased use for this indication after the first year (2 year 1, 10 year 2, and 7 year 3). The median length of stay (LOS) for this monitored cohort was 8 days with a mean of 9.9 days when a fiftyone day outlier was included in the cohort. When the outlier is excluded, the average LOS is 7.5 days with a mode of 6 . The national average for arrest patients is around 5 days (www.hcup-us.ahrq.gov). Because the diagnosis-related group (DRG) and reason for arrest was quite varied within this monitored cohort, comparisons of costs, LOS and outcomes for non-monitored cases over the same 3-year period, or even in a prior 3-year period, could not be made. However, the availability and increasing utilization of cvEEG is presumed to be representative of the perceived impact on care.

Seizures or status epilepticus were identified in $27 \%$ of cvEEG studies ordered (Table 1). Mortality for this group was high, 9/25 (36\%); however, overall mortality for patients undergoing cvEEG recording was high 24/92 $(26 \%)$. Once detected, seizures were well controlled in
$80 \%$ of the patients $20 / 25$, particularly in cases of status epilepticus in which $94.7 \%$ (18/19) were controlled. There were 5 cases in which seizures were not controlled and in all 5 , either care was withdrawn or the patients were sent to hospice. These decisions were not based on the presence of seizures alone, but were due to other underlying medical issues that impacted prognosis. Seizures were seen in a variety of clinical situations, the most common being patients who developed acute changes in mental status during their admission (Table 2). Witnessed seizures with or without altered mental status and cardiac arrest were also common clinical indications. The final facility diagnosis varied widely compared to the clinical indications (Table 2). These patients clearly demonstrated clinical impact as they would have required interfacility transfer to the main Duke Hospital prior to initiation of cvEEG. The initiation of this line also reduced delay in detection and treatment of seizures as well as any potential complications related to transport. From personal communication with the ICU faculty, they felt more comfortable treating patients with seizures and not transferring patients that were admitted for seizure activity now that they had cvEEG. At least two documented outside transfers were accepted to this facility because they had the ability to perform cvEEG monitoring. The change in the direction of transfers was a key indicator of success for the program and was a clear sign of clinical impact.

\section{Financial Impact}

Financial impact was assessed in two ways, cost savings and revenue generation. Two factors were explored for cost savings, the use of templates to reduce the need to hire additional technologists and the prevention of transfers to the main hospital for cvEEG monitoring. For revenue generation, there was potential for critical care billing for time in EEG lead placement, new revenue around study interpretation, and revenue around retention of the patients in the ICU as measured by the direct contribution margin on the cohort of patients that were not transferred. Additional potential value of the service includes increased DRG complexity, which could lead to better mortality index and care quality reporting for the hospital. However, our database was not adequate to answer this and so it could not be formally assessed here. The costs and revenues are summarized in Table 3 and discussed in detail below.

By design, service line initiation costs were minimal except for IT support and the authors' personal time in implementation. It was hypothesized that the prevention of transfers for monitoring would be a large cost savings, as each transport averaged $\$ 2750$ (range of $\$ 900-\$ 4600$ in 2015 US dollars). In review of the indication for the study, 
Table 2 Diagnoses and clinical indications for patients found to have seizures on cvEEG

\begin{tabular}{lll}
\hline Diagnosis-related group & Number of cases & Clinical indication \\
\hline Respiratory system diagnosis W ventilator support & 2 & AMS \\
Other digestive system or procedures W MCC & 1 & AMS \\
Intracranial hemorrhage or cerebral infarction W C & 2 & AMS, Sz \\
Traumatic stupor coma, coma <1 h W CC & 1 & AMS \\
Cardiac defib implant W cardiac cath W/O AMI/HF/SH & 1 & AMS \\
Other disorders of nervous system W MCC & 1 & CA \\
Seizures W/O MCC & 2 & AMS, Sz \\
Seizures W MCC & 4 & AMS, AMS + Sz \\
Acute ischemic stroke W use of thrombolytic agent & 1 & AMS \\
Trach W MV 96+ hours OR PDX EXC face mouth neck W/ & 3 & CA, AMSX2 \\
Septicemia or severe sepsis W MV 96+ hours & 4 & CA, AMSX2, Sz \\
Other ear, nose, mouth, throat diagnoses W MCC & 1 & AMS \\
Cranial peripheral nerve disorders W MCC & 1 & AMS \\
Cardiac arrhythmia conduction disorders W MCC & 1 & CA \\
\hline
\end{tabular}

$A M I$ acute myocardial infarction, $A M S$ altered mental status, $C A$ cardiac arrest, $C C$ complications or comorbidities, EXC except, $H F$ heart failure, $M C C$ major complications or comorbidities, $M V$ mechanical ventilation, $P D X$ principal diagnosis, $S H$ shock, $S z$ seizures, $W$ with, $W / O$ without it was determined that transfer was prevented in 53 of the 92 requested patient studies. The addition of cvEEG was not considered to have prevented transfers of patients that were already retained and managed at DRH without cvEEG. Cardiac arrest patients are an example, as these patients were being retained and managed without EEG prior to the initiation of the program. Patients with clinical seizures, concern for non-convulsive seizures, or suspected status epilepticus in which EEG was ordered were considered prevented transfers to Duke and would likely have been requested for transfer prior to the service. Prevention of these 53 transfer opportunities resulted in an estimated $\$ 145,750$ in average cost savings (range of $\$ 47,700$ $\$ 243,800)$.

No new technologists were hired over the 3 years of service. However, utilization of the templates by bedside providers has still not been implemented in a sustainable way. In the short term, additional service coverage after hours and on weekends was provided by the providers supporting the program with EEG interpretation initially, followed later by on-call technologists working at the main hospital. There was no additional pay associate with the provider coverage for study initiation which prompted the exploration of billing for critical care time for the hookup of templates. The use of the service during off-hours was curtailed by guidelines on the use and clinical indications for cvEEG that the facility put in place at the end of year two. While the added call coverage cost is being picked up by the health system and not the individual facility, this does represent an added cost for the service going forward and will need to be addressed as utilization grows.
Opportunities for new billing revenue were explored in addition to looking at the hospital revenue around this cohort of patients. From a billing perspective, critical care billing for EEG lead application was reimbursed on multiple occasions. The note used for supportive documentation included a brief history and indication for the request to evaluate for seizures, a brief neurologic exam, and plan for cvEEG monitoring and lead placement along with the time required to place the leads. Time required for placing the leads and performing the assessment and documentation varied from 35-60 min, and generally an hour of critical care was billed. No denials were seen using this approach. An estimated $\$ 6000$ in critical care billing was generated in this way. Additional professional billing for the interpretation of the studies can also be considered as new revenue. In this regard, an estimated $\$ 50,000$ in billing would be expected across the 3 years of studies based on an average reimbursement of $\$ 250$ per 24-h study. It was not possible to determine the exact amount earned because the readers also performed other EEG interpretation and critical care services at multiple facilities within the health system.

On the facility side, revenues were considered to arise from retention of the patients and increased ICU census. To determine if this was the case, we looked at the direct contribution margin (DCM) for each patient that underwent cvEEG monitoring. Overall, cvEEG-monitored patients had a positive DCM of around $\$ 100,000$. When looking specifically at the retained patients that transfer was prevented, the DCM was about $\$ 75,000$ or three-fourth of the total margin for the monitored cohort. We had hoped that the cardiac arrest population would provide some control 
Table 3 Summary of estimated costs, revenues, savings, and margins associated with cvEEG service

\section{Potential annual costs}

\begin{tabular}{|c|c|c|c|}
\hline Resource & Estimated model cost & Description and application to presented model & $\begin{array}{l}\text { Presented } \\
\text { model costs }\end{array}$ \\
\hline Technologists & $\begin{array}{l}\text { Salary range is } \$ 38,000- \\
\$ 60,000 \text { per technologist }\end{array}$ & $\begin{array}{l}\text { All EEG programs need at least one technologist, which is a sunk and shared } \\
\text { cost, to provide quality oversight and ensure all studies are performed } \\
\text { correctly and the studies are stored properly as part of the medical record. In } \\
\text { our model, two technologists were already at the facility. We reduced the } \\
\text { burden of the service on them by using templates for lead application. This } \\
\text { would be a shared cost across all EEG services }\end{array}$ & $\$ 0$ \\
\hline EEG machines & $\begin{array}{l}\$ 25,000-\$ 35,000 \text { per } \\
\text { machine }\end{array}$ & $\begin{array}{l}\text { The number of machines required is based on anticipated volume of studies. } \\
\text { Prices vary widely based on number purchased and brand; a reasonable } \\
\text { estimate is around } \$ 30,000 \text { USD per machine as a one-time cost. In our model, } \\
\text { this cost was avoided by using older machines that were being replaced at the } \\
\text { main hospital. Another alternative is to use a commercial vendor to provide } \\
\text { the technologist, machines and interpretations for one monthly cost that may } \\
\text { be lower than the ongoing cost of ownership }\end{array}$ & $\$ 0$ \\
\hline $\begin{array}{l}\text { Server/EEG } \\
\text { network }\end{array}$ & $\$ 10,000-\$ 20,000$ & $\begin{array}{l}\text { In order to support remote review and long-term storage of the studies, a central } \\
\text { server and network will need to be established. This is often sold as part of an } \\
\text { EEG-monitoring system and varies in price based on network specifications } \\
\text { and integration requirements. In our approach, we used the existing network } \\
\text { hosted by the main hospital. As above, some commercial vendors can provide } \\
\text { and maintain this at a reasonable cost }\end{array}$ & $\$ 0$ \\
\hline $\begin{array}{l}\text { Network } \\
\text { infrastructure }\end{array}$ & $\$ 5,000->\$ 100,000$ & $\begin{array}{l}\text { This can be the largest cost associated with this service. This is the cost of } \\
\text { pulling hardwired network connection ports to the rooms that will be used to } \\
\text { provide the monitoring. In our model, the ICU had recently been renovated } \\
\text { and there were network ports already available in every room. A new network } \\
\text { switch was required for all rooms to be active. Wireless network access has } \\
\text { been unreliable for this service in our experience; however, with continuous } \\
\text { innovation in the area of wireless network connectivity, this may be an option } \\
\text { in the near future and reduce the infrastructure cost }\end{array}$ & $\$ 5,000$ \\
\hline $\begin{array}{l}\text { Lead } \\
\text { placement } \\
\text { templates }\end{array}$ & $\$ 35-\$ 100 /$ template & $\begin{array}{l}\text { These are single use color-coded templates that allow non-technologists to place } \\
\text { EEG leads on the patient. They cost about } \$ 100 \text { USD per unit but are cheaper } \\
\text { than many alternative staffing models using technologists. In our model, these } \\
\text { were used to reduce the application times for the technologists and to provide } \\
\text { the capacity to use other providers to initiate studies. This created a revenue } \\
\text { opportunity as detailed below }\end{array}$ & $\$ 5,000 /$ year \\
\hline $\begin{array}{l}\text { EEG } \\
\text { interpretation }\end{array}$ & $\begin{array}{l}\text { Hiring a full-time } \\
\text { neurologist } \$ 150,000- \\
\$ 300,000\end{array}$ & $\begin{array}{l}\text { This represents the most expensive and most limited resource in the list. The } \\
\text { number of skilled readers is small nationally and internationally. Hiring and } \\
\text { retaining a reader is a challenge, and likely two readers would be required to } \\
\text { cover the service year-round. In our model, we used existing readers providing } \\
\text { coverage to the main hospital which turned this potential cost into revenue } \\
\text { (see below). Again, commercial systems can also broker monitoring and } \\
\text { interpretations of the studies as part of an overall service at a cost that is a } \\
\text { fraction of hiring providers }\end{array}$ & $\$ 0$ \\
\hline $\begin{array}{l}\text { Interfacility } \\
\text { transfer }\end{array}$ & $\begin{array}{l}\$ 2750 \text { (range of } \$ 900- \\
\$ 4600)\end{array}$ & $\begin{array}{l}\text { This is the cost for transferring a patient by ambulance from one hospital to } \\
\text { another hospital within the same health system. The two hospitals are about } 5 \\
\text { miles apart; costs would be higher for greater distances }\end{array}$ & $\$ 0$ \\
\hline $\begin{array}{l}\text { Total } \\
\text { estimated } \\
\text { costs }\end{array}$ & $\begin{aligned} \$ 50,000 & + \text { shared year } 1 \\
\$ 5000 & + \text { shared }\end{aligned}$ & $\begin{array}{l}\text { For year one, assumes one EEG machine, volume of } 30 \text { studies per year, and the } \\
\text { lowest cost amount for each fixed cost. Shared costs for technologist and } \\
\text { reader and transfer costs are not included }\end{array}$ & $\begin{array}{l}\$ 10,000 \text { yea } \\
1, \$ 5000\end{array}$ \\
\hline
\end{tabular}


Table 3 continued

\begin{tabular}{|c|c|c|c|}
\hline \multicolumn{4}{|c|}{ Potential annual revenues/savings } \\
\hline Source & Estimated model revenue & Description and application to presented model & $\begin{array}{l}\text { Presented model } \\
\text { revenue }\end{array}$ \\
\hline $\begin{array}{l}\text { Study } \\
\text { interpretations }\end{array}$ & $\$ 250 /$ study & $\begin{array}{l}\text { Interpretation of cvEEG studies is associated with a payment for } \\
\text { services on the order of about } \$ 250 \text { USD per } 24-\mathrm{h} \text { recording. This } \\
\text { represented new revenue in our model where the service provides } \\
\text { additional studies for the reader who was already salaried for EEG } \\
\text { reading at the main hospital }\end{array}$ & $\begin{array}{l}\$ 7500(30 \text { studies per } \\
\text { year) }\end{array}$ \\
\hline $\begin{array}{l}\text { Lead } \\
\text { application }\end{array}$ & Technical fee $\$ 500-\$ 2000$ & $\begin{array}{l}\text { While this can be a cost driver, in our model using templates, we were } \\
\text { able to bill for critical care time associated with the lead placement } \\
\text { and this generated additional new revenue. A technical fee can be } \\
\text { charged by the technologists when one is used for lead placement, } \\
\text { which will also generate revenue }\end{array}$ & $\begin{array}{l}\$ 9000 \text { (mean } \\
\text { collection of } \$ 300 / \\
\text { study day) }\end{array}$ \\
\hline $\begin{array}{l}\text { Reduced } \\
\text { interfacility } \\
\text { transfers }\end{array}$ & $\$ 2750 /$ transport (mean cost) & $\begin{array}{l}\text { This was a critical aspect to our model in which our goal was to } \\
\text { reduce the need to transfer between hospitals in our system. While } \\
\text { this is technically a reduction of cost, payments for transport are } \\
\text { highly variable and so the ability to prevent these can result in } \\
\text { significant cost reductions over time as shown in our model }\end{array}$ & $\begin{array}{c}\$ 48,600 \text { (prevented } \\
18 \text { transfers/year) }\end{array}$ \\
\hline $\begin{array}{l}\text { Increased care } \\
\text { complexity }\end{array}$ & $\begin{array}{l}\text { Variable (on the order of } \\
\text { thousands of dollars) }\end{array}$ & $\begin{array}{l}\text { In the USA, hospitals are paid based on the diagnosis reported for the } \\
\text { hospitalization or the DRG. For any given DRG, the payment is } \\
\text { higher if there are additional clinical factors that increase the } \\
\text { complexity and complicate care delivery. Identification of seizures } \\
\text { and status result in an increased complexity of care and higher } \\
\text { payments for some DRGs, which represents new revenue }\end{array}$ & $\begin{array}{l}\text { NA (not able to } \\
\text { measure, included } \\
\text { in DCM) }\end{array}$ \\
\hline $\begin{array}{l}\text { Decreased } \\
\text { length of stay }\end{array}$ & $\begin{array}{l}\text { Variable by center (average } \\
\text { ICU day cost) }\end{array}$ & $\begin{array}{l}\text { The length of stay (LOS) refers to the duration of hospitalization. } \\
\text { While we lacked sufficient baseline data to show a reduction in } \\
\text { LOS, it is reasonable to expect that early detection and treatment of } \\
\text { seizures causing altered mental status will result in decreases in } \\
\text { hospital LOS. In addition, early prognosis is facilitated in some } \\
\text { situations such as cardiac arrest. Finally, the need for transfer in the } \\
\text { past delayed identification of seizures by several hours and added a } \\
\text { minimum of } 24 \text { h to the LOS; this was prevented in our model }\end{array}$ & $\begin{array}{l}\text { NA (not able to } \\
\text { measure, included } \\
\text { in DCM) }\end{array}$ \\
\hline $\begin{array}{l}\text { Increased daily } \\
\text { census }\end{array}$ & $\begin{array}{l}\text { Variable (average case } \\
\text { margin } \mathrm{X} \text { increase in daily } \\
\text { census) }\end{array}$ & $\begin{array}{l}\text { The daily census refers to the average number of patients in the } \\
\text { facility on a daily basis. In the current study, we showed a reduction } \\
\text { in patients transferred out and new admissions related to the new } \\
\text { service, both of which will lead to an increased average daily census }\end{array}$ & $\begin{array}{l}\text { NA (not able to } \\
\text { measure, included } \\
\text { in DCM) }\end{array}$ \\
\hline $\begin{array}{l}\text { Total estimated } \\
\text { revenues }\end{array}$ & $\begin{array}{l}\$ 77,500+3 \text { variable } \\
\text { revenues }(\mathrm{DCM})\end{array}$ & $\begin{array}{l}\text { For the estimated model, assumed a volume of } 30 \text { studies and } 20 \\
\text { prevented transfers per year }\end{array}$ & $\begin{array}{l}\$ 65,100+\$ 25,000 \\
\quad(\mathrm{DCM})\end{array}$ \\
\hline \multicolumn{4}{|l|}{ Estimated margin } \\
\hline & Estimated model & Description and application to presented model & Presented model \\
\hline 3-year margin & $\$ 172,500$ & $\begin{array}{l}\text { These are estimated based on low end estimates for year } 1 \text { fixed costs } \\
\text { and do not include the shared costs of a reader and technologist. For } \\
\text { the estimated model, it is assumed a volume of } 30 \text { studies and } 20 \\
\text { prevented transfers per year }\end{array}$ & $\$ 250,300$ \\
\hline $\begin{array}{l}\text { Breakeven } \\
\text { point }\end{array}$ & Year 1 & $\begin{array}{l}\text { This is the estimated time at which revenues will exceed the year } 1 \\
\text { cost to start the service }\end{array}$ & 3 months \\
\hline
\end{tabular}

All monetary values are in 2015 United States dollars

$D C M$ direct contribution margin, $D R G$ diagnosis related group, $E E G$ electroencephalography, ICU intensive care unit, $L O S$ length of stay, $U S D$ United States dollars 
comparison data; however, this group had a heterogeneous collection of DRGs which precluded the creation of a comparison cohort. As a result, further comparisons of DCM, care costs, and LOS could not be made. Despite this, we can conclude that retention of this new population of patients did not result in losses for the facility and in conjunction with the average transfer cost savings resulted in an estimated net recovery of $\$ 245,000$.

\section{Discussion}

We report here the successful implementation of a continuous video-EEG-monitoring service at a community hospital and the clinical impact and cost savings produced by the service. We have shown that implementation of cvEEG at community hospitals is financially feasible and practical. The addition of the service allows expansion of critical care capability at the center and resulted in cost savings by reducing transfers out, production of new revenue, and retention of patients.

Adoption of the service has been slow but steady. Adoption of cvEEG in a medical/surgical ICU at the community level lagged when compared to the medical ICU at Duke Hospital in the first 3 years of service following development and implementation of cvEEG by Dr. Kolls in 2007. This may be due to the more mixed cardiac and medical focus of the community ICU since the ICUs were staffed by many of the same medical ICU providers. The differences are also interesting given the significant data to indicate the importance of monitoring and the high level of awareness among the providers who have trained and worked at the main hospital where it has been a part of practice for many years. The relatively high mortality in this monitored cohort does not suggest a lower acuity in a community ICU. Alternatively, the high mortalities may indicate the severity of clinical state required to trigger general intensivists to consider neurologic status in the care and prognosis of the patient. Answers to these questions require further study.

The use of templates for assistance in lead placement fell short of the planned implementation as we were unable to find a consistent, willing pool of bedside providers beyond the technologists. Some members of the nursing staff were enthusiastic and willing to apply the leads; however, in the absence of a formal competency training pathway, nursing could not be allowed to perform this role. Despite this, we were able to show that practical implementation of template technology at an institution that does not use collodion for lead placements led to long-lasting, high-quality recordings over several days using primarily subdermal needle leads. There were no uninterpretable studies resulting from the lead placement approaches. No complications or needle injuries were reported over the 3-year period of use, indicating these systems offer a safe, high-quality, cost-effective alternative to collodion-based lead placement approaches.

Our work has clearly demonstrated that cvEEG at a community hospital has value, not only in providing a higher level of care in the ICU, but also financial feasibility. There are clear reductions in cost related to preventing transfers of these patients between hospitals, and little to no added costs for the service in our particular model. The caveat to this being the unknown cost of offhours coverage by technologists on call as the service grows. However, this could be minimized or avoided if the templates could be completely implemented [12]. The largest costs for initiating this service are related to technologists and recording hardware, and these were effectively mitigated in our service model. However, commercial services or partnerships with academic centers can allow for dramatic reductions or elimination of these costs and should be considered by any center wanting to implement this kind of monitoring service.

\section{Conclusion}

Implementation of cvEEG at community hospitals is financially feasible, practical, and clinically impactful. The addition of the service allows expansion of critical care capability at the center and resulted in cost saving by reducing transfers and producing new revenue for the community center as well as its providers. In all, an estimated $\$ 245,000$ in cost reduction and revenues was associated with the service over its first 3 years, which is likely a conservative estimate as most patients required ICU-level care and would have required a transfer at the higher end of the cost range. We also demonstrated a clinical impact of the service across several groups of medical ICU patients. The template and needle lead system implemented here was safe and effective over the 3 years. However, the use of templates for facilitation of lead placement fell short of the planned implementation as we were unable to find a willing pool of providers, beyond the existing technologists, to use this approach. In the absence of a formal competency training pathway, nursing could not be allowed to perform this procedure. Future efforts will be aimed at creating formal competency training, as well as the development of telemedicine-based neurocritical care consult services to support the appropriate use and interpretation of the cvEEG results into patient care at our community affiliates. 


\section{References}

1. Le Roux P, Menon DK, Citerio G, Vespa P, Bader MK, Brophy $\mathrm{GM}$, et al. Consensus summary statement of the international multidisciplinary consensus conference on multimodality monitoring in neurocritical care: a statement for healthcare professionals from the neurocritical care society and the European society of intensive care medicine. Intensive Care Med. 2014;40(9):1189-209.

2. Gavvala J, Abend N, LaRoche S, Hahn C, Herman ST, Claassen J, et al. Continuous EEG monitoring: a survey of neurophysiologists and neurointensivists. Epilepsia. 2014;55(11):1864-71.

3. Claassen J, Vespa P. Electrophysiologic monitoring in acute brain injury. Neurocrit Care. 2014;21(Suppl 2):S129-47.

4. Claassen J, Taccone FS, Horn P, Holtkamp M, Stocchetti N, Oddo M. Recommendations on the use of EEG monitoring in critically ill patients: consensus statement from the neurointensive care section of the ESICM. Intensive Care Med. 2013;39(8):1337-51.

5. Kolls BJ, Olson DM, Gallentine WB, Skeen MB, Skidmore CT, Sinha SR. Electroencephalography leads placed by nontechnologists using a template system produce signals equal in quality to technologist-applied, collodion disk leads. J Clin Neurophysiol. 2012;29(1):42-9.

6. Kolls BJ, Husain AM. Assessment of hairline EEG as a screening tool for nonconvulsive status epilepticus. Epilepsia. 2007;48(5):959-65.
7. Hirsch LJ, LaRoche SM, Gaspard N, Gerard E, Svoronos A, Herman ST, et al. American clinical neurophysiology society's standardized critical care EEG terminology: 2012 version. J Clin Neurophysiol. 2013;30(1):1-27.

8. Sondag L, Ruijter BJ, Tjepkema-Cloostermans MC, Beishuizen A, Bosch FH, van Til JA, et al. Early EEG for outcome prediction of postanoxic coma: prospective cohort study with cost-minimization analysis. Crit Care. 2017;21(1):111.

9. Hofmeijer J, Beernink TM, Bosch FH, Beishuizen A, TjepkemaCloostermans MC, van Putten MJ. Early EEG contributes to multimodal outcome prediction of postanoxic coma. Neurology. 2015;85(2):137-43.

10. Milani P, Malissin I, Tran-Dinh YR, Deye N, Baud F, Levy BI, et al. Prognostic EEG patterns in patients resuscitated from cardiac arrest with particular focus on generalized periodic epileptiform discharges (GPEDs). Neurophysiol Clin Clin Neurophysiol. 2014;44(2):153-64.

11. Cloostermans MC, van Meulen FB, Eertman CJ, Hom HW, van Putten MJ. Continuous electroencephalography monitoring for early prediction of neurological outcome in postanoxic patients after cardiac arrest: a prospective cohort study. Crit Care Med. 2012;40(10):2867-75.

12. Kolls BJ, Lai AH, Srinivas AA, Reid RR. Integration of EEG lead placement templates into traditional technologist-based staffing models reduces costs in continuous video-EEG monitoring service. J Clin Neurophysiol. 2014;31(3):187-93. 